\title{
Tiranía pedracista y derecho de insurrección: la justificación periodística a la rebelión yorkina de la Acordada en México (1828)
}

Pedraza Tyranny and right of insurrection: the journalistic justification to the Yorkino rebellion of the Acordada in Mexico (1828)

Ana Romero Valderrama

Resumen

Palabras clave

Abstract

Keywords

Investigadora independiente

Correo electrónico: ana.romero.valderrama@gmail.com

Doctora en Estudios Latinoamericanos por la Universidad de St. Andrews en Escocia (2011). Actualmente, explora el derecho de insurrección durante la primera república federal mexicana. Entre sus publicaciones destaca "Asociación e identidad 'imparcial': una propuesta alternativa a las logias masónicas en la administración de Guadalupe Victoria (1826-1828)”, en Mexican Studies/Estudios Mexicanos 33 (1), enero 2017.

La doctrina insurreccionista representó en México una temática substancial para la construcción nacional al fundamentar la legitimidad de la independencia y los prístinos gobiernos. Los políticos decidieron no mencionarla en la constitución de 1824, ya que tácitamente la consideraron ligada al derecho natural. Tras la rebelión de la Acordada en 1828 reconsideraron desde nuevos ángulos esta postura. La historiografía presenta escasos acercamientos a tal doctrina en la rebelión. Esta investigación busca subsanar dicha ausencia. Muestra de qué manera la prensa yorkina buscaría de forma previa no solamente justificarla, sino promoverla. Analiza de qué forma la prensa yorkina intentaría legitimarla al argumentar una opresión pedracista. Finalmente, revela distintas consecuencias de esta asonada para la cultura política venidera.

Derecho de insurrección, México, elección presidencial, tiranía, Pedraza, logia yorkina, 1828

The "right of insurrection" represented a substantial theme for the nation-building history in Mexico, especially in terms of legitimacy of the independence and the nascent authorities. Politicians decided not to mention it in the 1824 constitution, since they already tacitly accepted its existence as a natural right. Nevertheless, after the 1828 Acordada rebellion, most politicians reconsidered their position. The insurrectionist doctrine claimed during the rebellion has not been addressed by historiography. Therefore, this article aims to fill in the missing political analysis. In the first place, it demonstrates that the yorkinos (Lodges of York) periodicals not only had previously sought to justify the revolt, but that they had actually set out to promote it. In the second place, it examines the arguments used to legitimize the revolt arguing a pedracista oppression. Finally, it explains some consequences of the uprising for the nineteenth-century political culture.

Right of insurrection, Mexico, presidential election, tyranny, Pedraza, Lodge of York, 1828

Recibido/Received

Aprobado/Approved
14 de noviembre de 2017

12 de abril de 2018 


\title{
Tiranía pedracista y derecho de insurrección: la justificación periodística a la rebelión yorkina de la Acordada en México (1828)
}

\author{
Ana Romero Valderrama
}
La república mexicana no será más el patrimonio de los tiranos.
El espíritu de Hidalgo influye incesantemente en el alma de cada mexicano, y esta suma prodigiosa de espíritu público, forma una revolución permanente contra toda empresa liberticida.

-Espíritu Público, septiembre 16, 1828

La rebelión de la Acordada no ha recibido la debida consideración en la historiografía mexicanista. Una situación paradójica, ya que entonces y en años siguientes no solamente estimuló innumerables reflexiones y discusiones, sino que en la historia de la época decimonónica representó una referencia obligada al evocar momentos definitorios de la fundación nacional. Tal indiferencia podría atribuirse a la principal imagen asociada a esta revuelta. La rebelión de la Acordada simbolizó un heraldo trágico que anunció el momento preciso en que la nación inició el largo camino de degradación e inestabilidad gubernativa con principios confusos y disturbios perpetuos. ${ }^{1}$ Esta lectura negativa derivaría principalmente de los autores testimoniales, continuaría en las décadas venideras y sería acogida en la siguiente centuria. José María Lafragua resumiría la perspectiva dominante entre servidores públicos e historiadores al calificarla de nota aleccionadora sobre fallas, corrupciones y distorsiones políticas de los años

\footnotetext{
${ }^{1}$ Rivera (1873, v. II, p. 129, 130).
} 
germinales. ${ }^{2}$ Los principales historiadores de las primeras narrativas de la construcción nacional produjeron estas obras patrocinados por la autoridad gubernativa. Buscaron ilustrar momentos gloriosos de las incipientes instituciones, y evitaron los acontecimientos "caóticos" o "desafortunados" que revelaran la debilidad estatal. ${ }^{3}$ Posteriormente, los historiadores revisionistas buscaron recobrar diferentes sucesos incómodos de aquellos años, pero no abordaron la rebelión de la Acordada como temática central. Únicamente Silvia M. Arrom en "Popular Politics in Mexico City: The Parián Riot, 1828" desentrañaría de forma minuciosa la participación de "los léperos" en el asalto del mercado del Parían durante la asonada. ${ }^{4}$ Igualmente, la presente investigación explica la lógica insurreccionista detrás de la rebelión de la Acordada. No obstante, adopta una perspectiva distinta, ya que analiza los argumentos ofrecidos por los principales promotores de la revuelta.

La rebelión de la Acordada inspiró varios escritos (planes) redactados en distintos momentos por algunos líderes implicados. No obstante, estos textos presentaron las motivaciones rebeldes de forma escueta, ya que supusieron una cierta familiaridad de los lectores con las circunstancias expuestas. Una manera de acercarnos de forma detallada a las argumentaciones subversivas es analizar los motivos desplegados en la prensa partidaria de los insurrectos. Especialmente porque, varias semanas antes de que la revuelta estallara, diferentes editores y colaboradores manifestaron razones similares a las presentadas después por los mismos pronunciados. Tal semejanza de ninguna forma sería fortuita. Al estallar la revuelta, el Correo de la Federación Mexicana representó la principal publicación periódica de los yorkinos. El Correo nació en la capital mexicana en noviembre de 1826 y epitomizó la tendencia radical de los yorkinos. Contó con diferentes editores y colaboradores (e.g. Lorenzo Zavala, Anastasio Zerecero, Rafael Gondra, José María Alpuche e Infante y José Manuel Herrera).

\footnotetext{
2 Lafragua (1987, p. 41, 42).

3 Los principales testigos que discutieron la rebelión de la Acordada fueron: Zavala (1845); y Tornel y Mendívil (1985). La mayoría de los historiadores que escribieron las primeras historias de la época independiente repitieron la interpretación presentada por ambos políticos e historiadores. Véase Riva Palacio (1884-1899); y Reyes Heroles (1957-1961).

4 Véase Arrom (1988, p. 245-268). Para una obra que aborda la rebelión de la Acordada al estudiar la primera república federal mexicana, véase Costeloe (1996, p. 189-216).
} 
Aunque habitualmente los nombres de los escritores relacionados a artículos, editoriales y comunicados fueron desconocidos - pues los autores no firmaron los escritos-, se sabe que Zavala y Zerecero fueron líderes del Correo y la rebelión de la Acordada de forma simultánea. ${ }^{5}$ Por estos motivos, es posible considerar de gran relevancia la relación entre la publicación periódica y la revuelta.

Esta investigación presenta dos objetivos principales. En primera instancia, mostrar de qué manera el Correo no solamente buscó justificar la rebelión de la Acordada, sino fomentarla desde unos meses antes. En segunda instancia, analizar las estrategias discursivas usadas en esta publicación para legitimarla. Explicar de qué forma y por qué los yorkinos eligieron y re-significaron distintas nociones políticas con la intención de demostrar la opresión pedracista para apelar al "derecho de insurrección". De este modo, busca revelar la teoría insurreccionista yorkina y la forma en que acciones e ideas relacionadas a la interpretación yorkina del derecho de insurrección impactaron la manera en que las movilizaciones armadas fueron percibidas y abordadas en los años venideros.

La metodología está basada principalmente en estudiar el periódico yorkino líder. Revisa las diferentes secciones del Correo durante 1826-1828 para descifrar las distintas perspectivas de los yorkinos radicales sobre derecho de insurrección. Contrasta las últimas con los diversos contextos para encontrar las transformaciones en los usos de esta teoría y otras doctrinas relacionadas. De esta manera, muestra la originalidad de la interpretación yorkina durante los meses previos a la asonada. Al igual, estudia los pronunciamientos rebeldes (planes) de la Acordada, que fueron publicados entonces y después, y los escritos biográficos e históricos de Zavala al rememorar la revuelta -que sería el único líder que buscaría explicarla-. Posteriormente, señala los principales ejes conceptuales que estructuraron los argumentos yorkinos al buscar legitimar la revuelta, y explica de qué manera los yorkinos re-articularon los conceptos para presentar la justificación a la rebelión de la Acordada. Finalmente, confronta estos documentos yorkinos con textos redactados en diferentes momentos por

${ }^{5}$ Véase Tornel (1985, p. 80) y Águila Mejicana, en adelante Águila, “Comunicados”, febrero 18,1827 .

ESTUDIOS DE HISTORIA MODERNA Y CONTEMPORÁNEA DE MÉXICO 55, enero-junio 2018, 77-119

DOI: http://dx.doi.org/10.22201/iih.24485004e.2018.55.63803 
personajes o grupos cercanos y contrarios a los yorkinos, además de escritos de historiadores posteriores, para encontrar discrepancias y coincidencias.

Esta investigación está dividida en las siguientes secciones. La primera presenta el contexto político de la rebelión de la Acordada. La segunda desarrolla la discursiva usada por los yorkinos para explicar la tiranía de Pedraza (y así justificar la revuelta). La tercera identifica y analiza la manera en que los yorkinos usaron tal discursiva para legitimar la asonada y, finalmente, la cuarta señala unas consecuencias políticas de la teoría insurreccionista yorkina.

\section{La elección presidencial de 1828}

Las logias masónicas aparecieron de forma esporádica en Nueva España durante el siglo xviII. Pero hasta el siglo xix formaron varios grupos organizados con la llegada de masones entre soldados peninsulares y diputados gaditanos novohispanos. Entonces, los ritos escoceses combatieron los intentos absolutistas de autoridades francesas y españolas. Subsiguientemente, participaron en la lucha autonomista e independentista y, de esta manera, ganaron influencia. Tras la proclamación de independencia en 1821, los escoceses apoyaron una monarquía constitucional encabezada por la casa borbona, pero España rechazó tal propuesta. De manera que la asamblea legislativa otorgó en 1822 la corona imperial al héroe de la independencia Agustín de Iturbide, con la desaprobación de republicanos y borbónicos, incluidos los escoceses. A raíz de varios desencuentros entre Iturbide y la asamblea legislativa, en 1823 Iturbide disolvió esta última y los escoceses nuevamente se rebelaron contra los intentos absolutistas y participaron en la conspiración para derrocarle. Después de la derrota monárquica, en 1824 una alianza de republicanos y federalistas variopintos dominó en la asamblea legislativa. Estableció una república con una tendencia federal poderosa, redactó la constitución, y llevó a la presidencia al héroe insurgente Guadalupe Victoria. Los escoceses nuevamente resultaron defraudados, ya que unos prefirieron una monarquía y otros aceptaron una república, pero con una organización centralizada o federal moderada alternativa; a más de que no dominaron en la asamblea legislativa y tuvieron que conformarse con la vicepresidencia. No obstante, aceptaron la nueva gobernabilidad. En 1825, varios 
elementos de los nuevos grupos al poder consideraron que los escoceses todavía contaban con posibilidades de recuperar la influencia perdida. Así, resolvieron crear los ritos yorkinos para apoyar la república federal e instituciones y funcionarios adscritos a ésta y, al mismo tiempo, eliminar a los escoceses. ${ }^{6}$

Los yorkinos declararon que nacieron para la defensa de la independencia y los baluartes fundacionales de la actual gobernabilidad. ${ }^{7}$ Aseguraron que los escoceses eran contrarios a éstos y tenían una alianza con los españoles para destruirlos y retornar a la sujeción de España. ${ }^{8}$ De forma paralela, los yorkinos fomentaron la idea de una afrenta entre indios y mestizos pobres contra españoles y criollos ricos. Anunciaron que los desfavorecidos debían de ser reivindicados y los alentaron a presentar resistencia contra los privilegiados. ${ }^{9}$ Consiguientemente, promovieron la participación política de los sectores populares mediante diversos grupos representativos, espacios y tiempos. ${ }^{10}$ Los escoceses rechazaron "las exageraciones democráticas" que promovían los yorkinos. Apoyaron a aquellos que se consideraron atacados y, en consecuencia, se unieron con los grupos aristócratas, incluidos los españoles. ${ }^{11}$ De esta manera, los dos partidos fraguaron una imagen pública distintiva binaria, para referirse a ellos mismos y los contrarios, y colocaron en los opuestos etiquetas cargadas de prejuicios y miedos: los escoceses eran descritos "pro-españoles”, "borbonistas”, o "retrogradas", mientras los yorkinos eran llamados “extremistas", "jacobinos" o “demagogos". ${ }^{2}$ De manera creciente, ambas logias sostuvieron violentos enfrentamientos para dominar en los ámbitos gubernamentales.

\footnotetext{
${ }^{6}$ Escoceses y yorkinos recibieron estos nombres al adscribirse a los ritos de Escocia y York, respectivamente.

7 Tornel (1985, p. 46); Correo de la Federación Mexicana, en adelante Correo, “Editorial”, enero 18, 1828 y Bustamante (2003), septiembre 19, 1825.

${ }^{8}$ Águila, "Comunicados", septiembre 27, 1826.

9 Águila, "Comunicados", septiembre 23, 1826; Correo, "Editorial”, abril 19, 1828 y Zavala $(1845$, l, p. 258 y 263$)$.

10 Correo, "Editorial”, febrero 09, 1828 y Águila, “Comunicados", agosto 24, 1828.

${ }^{11}$ Cuevas (1954, p. 253 y 279).

${ }^{12}$ La aportación de María Eugenia Vázquez Semadeni a la historiografía resulta significativa, ya que debate acerca de la discusión pública sobre las supuestas diferencias entre ambas logias. Véase Vázquez (2010).
} 
Los yorkinos aumentaron su influencia política de forma paulatina. Simultáneamente, aprovecharon cada oportunidad para dañar a los escoceses, especialmente en dos acontecimientos durante 1827 y 1828: la conspiración pro-borbónica y la rebelión escocesa (también llamada "montañista", ya que sería iniciada por el coronel Manuel Montaño). En enero de 1827, una conjura orientada a eliminar la república para retornar a la monarquía hispana resultó descubierta y sofocada. La confabulación, organizada por Joaquín Arenas y peninsulares en ambos lados del Atlántico, involucró a destacados generales escoceses y, de esta manera, agravó la animosidad partidista. Los yorkinos no pudieron demostrar la participación de los escoceses, pero aprovecharon para alardear de su postura patriótica y demandar la expulsión hispana, a más de la destrucción de monárquicos, centralistas y otros enemigos, i.e. los escoceses. Después de varios meses de enfrentar ataques y la creciente fuerza de los yorkinos, varios escoceses decidieron lanzar una revuelta en diciembre de 1827 -a unos cuantos días de quedar aprobadas las leyes de expulsión- y resultaron vencidos en Tulancingo en enero de 1828. Los escoceses quedaron fracturados y los yorkinos se consideraron vencedores a unos cuantos meses de los procesos electivos para la presidencia, las asambleas de diputados federales y estatales y la mitad de senadores-. No obstante, constantes enfrentamientos y vientos electorales provocaron una transformación en las alianzas políticas al estimular una reformulación de las fuerzas existentes.

Desde 1826, varios individuos y sectores iniciaron una movilización política para frenar la preponderancia de las logias, especialmente de los yorkinos. Algunos de estos oponentes crearon nuevas formaciones políticas, e.g. los "imparciales" $y$, posteriormente, los novenarios. ${ }^{13}$ Los imparciales fueron miembros de la autoridad federal. Compartieron una perspectiva liberal, republicana, federalista y contraria a las logias, especialmente a las inclinaciones populares de los yorkinos. Explicaron que surgieron para plantear una cultura política alternativa a los partidos masónicos, ya que sus discusiones y ataques a las autoridades desestabilizaban a la nación. ${ }^{14}$ Gradualmente, crearon alianzas con individuos y grupos que se identificaron con tal propuesta y formaron una coa-

\footnotetext{
${ }^{13}$ Los novenarios fueron una unión de escoceses y anti-masónicos.

14 Romero (2017).
} 
lición poderosa. Al aproximarse la elección presidencial de 1828, destruidos los escoceses, imparciales y yorkinos protagonizaron una nueva confrontación al lanzar dos candidaturas opuestas y, de esta forma, polarizar las adscripciones políticas. Los yorkinos depositaron en los imparciales los viejos adjetivos adjudicados a los escoceses. Radicalizaron su plataforma orientada a fomentar la participación política de los sectores populares y, al mismo tiempo, apoyaron al héroe insurgente general Vicente Guerrero. Los imparciales dirigieron una alianza formada por anti-masónicos y yorkinos y escoceses desencantados, y respaldaron al secretario de Guerra y Marina general Manuel Gómez Pedraza. En septiembre, los congresos estatales sufragaron y dieron la victoria a Pedraza. Inmediatamente, autoridades federales y estatales, incluidas las yorkinas, apoyaron de forma pública los resultados. No obstante, al mismo tiempo, yorkinos y aliados cuestionaron los procesos electorales y realizaron distintas maniobras políticas para deslegitimarlos. ${ }^{15}$ Entre éstas, organizaron varias sublevaciones armadas, las que culminaron con la rebelión de la Acordada al finalizar noviembre de $1828 .^{16}$

Los líderes de la asonada fueron políticos yorkinos radicales -Zavala y Zerecero- y militares yorkinos y aliados -los coroneles Santiago García y José María de la Cadena, y los generales José María Lobato y Guerrero- que dirigieron armas rebeldes yorkinas de la capital nacional y Estado de México. ${ }^{17} \mathrm{~A}$ unos

15 Romero (2010, p. 165-195).

${ }^{16}$ Estos pronunciamientos tuvieron lugar entre septiembre y diciembre. En septiembre, el general Antonio López de Santa Anna inició la rebelión de Perote en Veracruz, a esta revuelta siguieron varias asonadas en distintos puntos de la república, la última revuelta sería en la Acordada en noviembre y diciembre de 1828. En la primera y la última rebelión, los rebeldes demandaron la sumisión de la autoridad gubernativa y la expulsión hispana, pero Perote manifestó una oposición abierta contra la victoria electoral de Pedraza, mientras que la Acordada se limitaría a señalar la tiranía pedracista como la razón para levantarse-aunque los textos de entonces aseguraron que todos sabían que la asonada estaba relacionada a la disputa electoral-. Ciertamente, ambos pronunciamientos fueron complementarios y marcaron la parte inicial y final de una seria concatenada de revueltas anti-pedracistas.

17 El “Ejército Libertador" publicó el 5 de diciembre un plan que demandaba la expulsión española y se ponía a los servicios del gobierno establecido. Estaba firmado por Zavala, Zerecero y todos los involucrados militares, excepto Santiago García que murió durante la revuelta y Guerrero que negó participar. Véase Lobato y Zavala (2003, 1, “anexos”). Cf. Bustamante, Voz de la Patria, junio 05, 1830. 
cuantos kilómetros de los recintos federales, el 30 de noviembre los sediciosos iniciaron la sublevación con varios disparos de cañón. Unas horas después, las fuerzas federales y los insurrectos comenzaron la lucha. $\mathrm{El} 3$ de diciembre, Guerrero se presentó momentáneamente en las afueras de la capital para alentar a los suyos. Entonces, Pedraza decidió renunciar a la secretaría y la futura presidencia, y escapar para terminar la afrenta. A pesar de estos dos reveses, las armas federales continuaron la lucha. El 4 de diciembre una turba de cerca de 5000 hombres y mujeres, incluidos soldados participantes en la rebelión de la Acordada, atacaron en el mercado del Parián numerosas tiendas pertenecientes a españoles y algunas casas de anti-yorkinos, de esta manera, aterrorizaron a la capital. Victoria permaneció en Palacio Nacional para preservar la presidencia y la legitimidad gubernativa, ya que los miembros de los otros poderes escaparon. Después de varios intentos de negociación, se rendiría y cedería a los requerimientos rebeldes para evitar una sangrienta guerra civil. De nueva cuenta, Zavala actuaría de líder y conseguiría que las demandas yorkinas fueran cumplidas, principalmente que Guerrero ocupara la Secretaría de Guerra y Marina $\mathrm{y}$, posteriormente, la presidencia. ${ }^{18}$

La opresión pedracista desde la perspectiva de la publicación periódica yorkina

\section{Correo de la Federación Mexicana}

Los líderes de la rebelión de la Acordada declararon que se rebelaron contra la opresión pedracista. ${ }^{19}$ En la proclama seguida a la revuelta, enunciaron que los mexicanos se levantaron para liberarse de los crueles eslabones de la conducta tiránica de Pedraza. ${ }^{20}$ Esta justificación no provocó gran sorpresa, ya que previamente otras voces pro-yorkinas sostuvieron reclamos parecidos. Dos meses

\footnotetext{
${ }^{18}$ Zavala (1845, II, p. 93-94).

19 Zavala (1845, II, p. 85 y 107-108) y Zerecero (1975, p. 87, pie de nota 8). Además de Tornel (1985, p. 344); y Paz (1829).

20 Lobato y Zavala (2003, 1, “anexos”).
} 
antes, el general Antonio López de Santa Anna ofreció la misma razón al iniciar la rebelión de Perote. La proclama santannista manifestaba:

Ha levantado su orgullosa cerviz la espantosa hidra de la tiranía. Los españoles insultan en la capital a los beneméritos mexicanos; la mayoría del senado, vendida a esta facción liberticida, persigue a los buenos patriotas con ofensa de la razón y desprecio de las leyes; la cámara de diputados, intimidada, subscribe a decretos de proscripción, semejantes a los que llenan las páginas sangrientas de la anterior revolución; la capital ofrece un espectáculo melancólico de pavor y espanto, por el terror que inspiran esas medidas de tiranía; la desconfianza, el espionaje, las prisiones, el luto, el llanto, son en el día la triste suerte de los mexicanos. En estas circunstancias ¿̇cómo había yo de permanecer indiferente? [...] Cuando un jefe imbécil tiene entregadas las riendas del gobierno al nuevo opresor de mis compatriotas. ${ }^{21}$

Igualmente, la prensa yorkina aludió a la tiranía de Pedraza para justificar una reacción armada contra la autoridad gubernativa. La publicación periódica Correo de la Federación Mexicana presentó dos registros diferentes al abordar las asonadas pro-yorkinas tras la victoria pedracista en las urnas. Los editores no llamaron de manera abierta a la sedición armada contra los poderes constituidos - posiblemente para evitar la acusación de incitarla-, pero la apoyaron de una forma distinta. Por una parte, en septiembre, después de estallar la rebelión de Perote, los editores no respaldaron de forma directa a Santa Anna, pero en la sección de "Noticias Nacionales" insertaron la proclama santannista y dos supuestas misivas ciudadanas que justificaban la sublevación de Perote. ${ }^{22}$ De esta forma intentaron demostrar que la asonada contaba con la sanción popular. Por otra parte, en diciembre, tras estallar la rebelión de la Acordada, los editores condenaron explícitamente en la página editorial las revueltas armadas que, decían, provocaban la intranquilidad pública. ${ }^{23}$ No obstante, enton-

\footnotetext{
${ }^{21}$ López (2003, 1, “anexos").

${ }^{22}$ Correo, “Noticias Nacionales", septiembre 12, 1828.

${ }^{23}$ Correo, "Editorial”, diciembre 01, 1828 y Correo, "Noticias Nacionales", diciembre 08, 1828.
} 
ces y en los meses previos a la asonada, divulgaron editoriales, artículos y comunicados en donde presentaron ejemplos de la actitud represiva de la autoridad gubernamental, los que justificaron una sublevación armada.

La argumentación yorkina contra Pedraza tenía dos rasgos fundamentales: por una parte, representaba una crítica que anteriormente había sido utilizada por otros sectores políticos -i.e. escoceses y novenarios-y, por otra parte, constituía una dramática reconsideración de la posición previa de ciertos yorkinos.

La labor gubernativa de Pedraza había sido cuestionada por numerosos políticos a causa de la historia política de éste. Por una parte, Pedraza sería acusado de hispanista-borbonista porque había pertenecido a las filas realistas, y sería calificado de iturbidista y monárquico porque había apoyado a Iturbide y había criticado la forma republicana al buscar apoyar al gobierno monárquico constituido. Por otra parte, la Secretaría de Guerra y Marina había sido criticada por la forma en que había reaccionado a dos grandes eventos: la conspiración pro-borbónica en enero de 1827 y la revuelta escocesa en diciembre de 1827 y enero de 1828. Antes de formar parte de la administración Victoria, Pedraza había pertenecido a los escoceses, pero al llegar a la oficina ministerial había abandonado esta logia y no había entrado en la nueva. A pesar de esta postura apartidista, la secretaría transmitía una imagen pública cercana a los yorkinos, pues respondía con condescendencia a brotes rebeldes yorkinos, pero no tenía la misma tolerancia con los escoceses. Testimonios de aquella época aseguraron que Pedraza tenía esta inclinación por dos motivos principales: venganza personal y ganancia política. Manifestaron que Pedraza utilizó la secretaría para zanjar una vendetta privada y partidista contra antiguos enemigos. Alegaron que éste aprovechó la conspiración pro-borbónica para golpear a Gregorio Arana, José Antonio Echávarri y Pedro Celestino Negrete, que eran prominentes generales y líderes escoceses. Al igual, acusaron a Pedraza de influjos anti-escoceses en la aprehensión de los involucrados en la rebelión montañista. ${ }^{24}$ Las acusaciones legales de escoceses y novenarios contra Pedraza no procedieron, pero no eliminaron los recelos, ya que, indudablemente, Pedraza ganó ventaja

24 Alamán (1852, V, p. 831, 832); El Sol, en adelante Sol, “Editorial”, marzo 28, 1827 y Correo, “Editorial”, abril 16, 1828. 
de la posición de los infortunados. En primera instancia, cobró una vieja deuda personal. ${ }^{25}$ En segunda instancia, conquistó la simpatía de los yorkinos y, de esta forma, fortaleció la Secretaría de Guerra y Marina y formó una alianza con éstos para atacar a los escoceses. En respuesta, escoceses y novenarios criticaron de manera constante y encarnizada la actuación de Pedraza -le acusaron de tiranía y demandaron su renuncia después de ambos acontecimientos-. Al mismo tiempo, yorkinos e imparciales defendieron con la misma fuerza a la secretaría y exaltaron la posición patriótica de Pedraza en la defensa nacional. ${ }^{26}$

La elección presidencial invirtió estas posturas de forma radical, después de que Pedraza surgió con la candidatura opuesta a los yorkinos. Varios escoceses decidieron olvidar las viejas rencillas contra Pedraza y respaldaron la candidatura para evitar una presidencia yorkina. Numerosos yorkinos moderados - principalmente miembros de la élite política, económica y militar dentro de la logia- decidieron apoyar a Pedraza y, consecuentemente, renegaron de la elección hecha por la cúpula yorkina. Por otro lado, los yorkinos radicales y algunos moderados cerraron filas con ésta. No solamente retiraron la ayuda a Pedraza, sino que emprendieron una campaña para desprestigiarle, en la cual la principal crítica a Pedraza sería la misma que aquella previamente presentada por escoceses y novenarios: la opresión. ${ }^{27}$ Esta transformación dramática forzaría a los yorkinos a explicar su nueva postura.

Los yorkinos fundamentaron esta mutación en la idea de que Pedraza ya no seguía la causa patriótica. ${ }^{28}$ Aseguraron que una personalidad patriota debía de mostrar una disposición extraordinaria para defender a la nación de los

${ }^{25}$ Se dijo que Pedraza atacó a Arana porque este último participó en una conspiración para formar causa contra Pedraza, la cual no procedió, pero de forma exitosa eliminó a Pedraza de la contienda presidencial en 1824. Supuestamente, Pedraza persiguió a los antiguos iturbidistas Negrete, Echávarri y Arana porque traicionaron a Iturbide, ya que apoyaron la rebelión contra la autoridad imperial en 1822. En 1827, la autoridad federal fusiló a Arana, pero no encontró evidencia de la participación de los otros dos en la conspiración pro-borbónica y quedó obligada a liberarlos. No obstante, se acogió a las leyes de expulsión hispana para expatriar a ambos veteranos insurgentes -y posibles candidatos presidenciales-.

${ }^{26}$ Correo, "Editorial”, abril 16, 1827 y Águila, "Editorial”, marzo 24, 1827.

27 Cf. Sol, "Comunicados", junio 27 y 31, 1827.

${ }^{28}$ Correo, “Editorial”, agosto 08, 1828. Cf., Correo, “Editorial”, febrero o8, 1828. 
contrarios a ésta. Subrayaron que la máxima actitud patriota consistía en formar parte de los héroes insurgentes y subsiguientes herederos de la lucha libertaria, i.e. los yorkinos, entonces, en demostrar una clara animadversión por los enemigos de éstos. Enfatizaron la diferencia entre los servicios patrióticos de Guerrero y Pedraza al subrayar la devoción ejemplar de Guerrero en la guerra de independencia. Al igual, buscaron descalificar a Pedraza al asegurar que, a diferencia de Guerrero, Pedraza compartía las ideas de los traidores. Proporcionaron diversos ejemplos en los que Pedraza aparecía con un pasado anti-patriótico: monárquico, realista, pro-hispanista, borbonista, iturbidista y escocés. Aseguraron que, para ganar la presidencia, Pedraza retornaba a las viejas andanzas, ya que evidenciaba una renovada amistad con españoles y aquellos opuestos a los patriotas yorkinos -i.e. escoceses, novenarios e imparciales-. ${ }^{29}$ Los yorkinos mostraban una pintura grotesca de los supuestos seguidores de Pedraza en donde mezclaban "los mayores enemigos" de la nación en una unión perversa de celebraciones subsiguientes a la victoria pedracista. Decían:

Se brindará por el hombre de la fibra, por los montañistas, por los gachupines, por los escoceses, por los novenarios, por los editores del Águila y del Sol, por los imparciales, por la destrucción de los yorkinos, por el centralismo, por el cumplimiento del Plan de Iguala y tratados de Córdova, por los cinco señores, por la mayoría del senado, por la minoría de la cámara de diputados, por el degüello de Oaxaca, por los aceiteros, y muchísimos brindarán también por Fernando xvir. No se dejarán de proyectar carreras y bailes como los que hubo en las vísperas de la salida de Bravo para Tulancingo. ${ }^{30}$

A más de presentar a Pedraza con esos rasgos anti-patrióticos, la prensa yorkina iniciaría una campaña fundamentada en los temores de los mexicanos. De manera gradual, introducía la idea de una alarma nacional. Aseguraba que crecientes incertidumbres y amenazas estaban relacionadas a la autoridad otorgada a Pedraza. Cimentaba esta perspectiva en dos argumentos principales. Pedraza constituía una figura tiránica que ya mostraba tendencias represivas

29 Correo, “Comunicados", agosto 13, 1828.

30 Correo, “Comunicados", agosto 28, 1828. 
en la secretaría, y parecía aumentarlas más y más a causa de la elección presidencial. Al igual, Pedraza apoyaba una reconquista borbónica en tierras mexicanas. De ambos modos, representaba una amenaza para la próxima administración y la continuidad de la república federal.

Los escritos del Correo buscaban alimentar los miedos de una reconquista y, al mismo tiempo, proporcionar argumentaciones convincentes de que Pedraza al llegar a la presidencia podría renunciar a ésta para retornar la nación liberada a España. Presentaban funestos recuentos de la época colonial hispana, y agregaban que los mexicanos debían de temer una restauración de la corona española. ${ }^{31}$ Los yorkinos redactaban artículos y comunicados con títulos relativos al retorno borbónico e, inclusive, llegaban a aseverar que las potencias europeas apoyaban a Pedraza y que la triple alianza estaba enojada por los votos a favor del héroe insurgente. ${ }^{32}$ Así creaban una atmósfera de reciente y muy activa confabulación entre Pedraza, escoceses y españoles. Aseguraban:

Sepan vds. Que el gran consistorio escocés de los soberanos príncipes del real secreto que preside el realista D. Manuel Gómez Pedraza, acordó en una de sus tenebrosas sesiones [...] escribir inmediatamente a la Habana, para que Vives envíe tres o cuatro buques con alguna gente a las costas de Tabasco a fin de proteger el pronunciamiento que proyectan a favor de España en el caso de que salga electo el héroe del Sur. ${ }^{33}$

De forma paralela, la prensa yorkina inició una cruzada para desacreditar la Secretaría de Guerra y Marina. Otorgó una relevancia desmedida a una nueva querella para dar novedad a previas acusaciones escocesas sobre la opresión pedracista. Profundizó en una disputa oaxaqueña para explicar la represión ministerial. De esta forma, elevó una problemática estatal a la arena nacional. En agosto, Oaxaca tendría una atmósfera explosiva. Al mismo tiempo que la ciudadanía oaxaqueña sufragaba a la legislatura estatal entrante, la legislatura saliente se preparaba para votar en la elección presidencial. De suerte que los

\footnotetext{
${ }^{31}$ Correo, "Editorial”, agosto 14, 1828.

32 Correo, "Editorial”, septiembre 12, 1828.

33 Correo, “Comunicados”, agosto 20, 1828.
} 
conflictos locales serían una buena excusa para otorgarles una conexión partidista con los nacionales. Los grupos contendientes en Oaxaca eran los aceites y los vinagres. En los comicios populares, ambos grupos rivalizaron por las mesas electorales y se enfrentaron de forma violenta hasta terminar en una balacera con heridos y tres muertos, todos vinagres. ${ }^{34}$ La prensa yorkina apoyaba la causa de los vinagres, ya que se identificaba con su postura anti-hispana y ultra-democrática. Haría suya la causa de éstos y, al mismo tiempo, trasladaría la confrontación "patriotas contra anti-patriotas" (con sus respectivas características) al ámbito nacional. El Correo relacionaba aceites con escoceses y peninsulares ricos y, por otro lado, vinagres con yorkinos pobres. De manera que durante la contienda presidencial aclaraba que los vinagres eran partidarios de Guerrero y los aceites respaldaban a Pedraza. ${ }^{35}$ Afirmaba que la Secretaría de Guerra y Marina protegía la represión hecha por las autoridades oaxaqueñas (que eran aceites) porque buscaba la complacencia de la legislatura estatal para ganar los sufragios oaxaqueños en la elección presidencial. Explicaba que, de esta manera, Pedraza ya trazaba la senda de absolutismo desmedido. ${ }^{36}$

Paulatinamente, los escritores del Correo relacionaron la acusación de intervención ministerial desmedida en Oaxaca a toda la república. Expusieron que los intereses de la autoridad debían ser idénticos a los intereses de la nación..$^{37}$ No obstante, aseguraron, Pedraza usaba la oficina para reorganizar y movilizar las fuerzas armadas de la nación para beneficios propios. De esta forma, aseveraron, Pedraza violentaba la constitución y evidenciaba sus tendencias tiránicas. ${ }^{38}$ Declararon que Pedraza usaba la potestad ministerial para eliminar a enemigos y posibles oponentes a la presidencia. Una acusación que no parecía inverosímil para muchos, ya que evocaba la previa vendetta de Pedraza y las subsecuentes imputaciones de escoceses y novenarios. Posteriormente, los yorkinos señalaron que Pedraza quería silenciarlos porque representaban a los patriotas. ${ }^{39}$ Clamaron que la Secretaría de Guerra y Marina

\footnotetext{
34 Guardino (2005, p. 197-202).

35 Correo, “Miscelánea”, agosto 23, 1828.

${ }^{36}$ Correo, "Editorial”, agosto 16, 1828.

37 Correo, “Miscelánea”, octubre 21, 1828.

${ }^{38}$ Correo, “Editorial”, octubre 10, 1828.

39 Correo, “Comunicados”, agosto 30, 1828.
} 
sustituía a patriotas por escoceses e imparciales y que ya había iniciado persecuciones y represiones no solamente contra los partidarios descontentos, sino contra simples ciudadanos. ${ }^{40}$ Manifestaron que los pedracistas acudían a espionajes, persecuciones y medidas inquisitoriales contra familiares, amigos y vecinos, y que llegaban a arrancar de los hogares a ciudadanos para arrastrarlos por las calles inmundas. ${ }^{41}$ Anunciaron que Pedraza tenía una lista de los primeros proscriptos, y que ya había iniciado las primeras aprehensiones. ${ }^{42}$ Dijeron:

Allanan las casas: se examinan y secuestran papeles sin formalidad alguna legal: se pone a los hombres incomunicados sin que proceda más que la delación calumniosa de cualquier espía, de manera que llega a tanto la persecución, que los hombres que han vertido ideas liberales o se han asociado con los exterminados, hoy andan los unos prófugos, los otros escondidos en los subterráneos y los que no, llevan pintado el pavor en el rostro. ${ }^{43}$

Artículos, comunicados y editoriales presentaban una imagen desoladora. Aseguraban que en Oaxaca había sangre inocente derramada. Apuntaban: "infinidad de heridos y muertos hechos por la fuerza armada, han quedado tendidos en la plaza pública. Los enemigos de la nación, los amigos de Pedraza, han triunfado. "VENGANZA, VENGANZA, VENGANZA; la venganza por la ley o renunciemos a la libertad o independencia.”44 Decían que Pedraza quería sangre, porque solamente la de Oaxaca no le satisfacía. ${ }^{45}$ Preguntaban a Pedraza:

¿Qué harías si fueses presidente, cuando haces tanto siendo nomás ministro? [...] los cadáveres serían amontonados: ¿Pero qué importa? Estos mismos cadáveres te servirían de escalones al trono que tanto apeteces. Allí verías si te convenía reinar por ti, o si te sería más útil vender de nuevo esta tu infelice

\footnotetext{
$4^{\circ}$ Correo, "Editorial”, agosto 10, 1828.

${ }^{41}$ Correo, "Editorial”, agosto 21, 1828.

42 Correo, “Editorial”, agosto 29, 1828.

43 Correo, "Comunicados", agosto 17, 1828.

44 Correo, "Editorial”, septiembre 05, 1828.

45 Correo, “Comunicados”, agosto 30, 1828.
} 
patria a tu antiguo adorado amo. Lo que no te fue posible hacer como capitán esclavo, lo harías como capitán libre, como emperador o como rey. ${ }^{46}$

El Correo acompañaba esta visión de persecución con calificativos designados a actos dignos de "sangrientos sultanes", y a una represión despótica, tiránica o dictatorial. ${ }^{47}$ Exhortaba a los patriotas mexicanos: "tengan valor y dignidad para sufrir las persecuciones [terribles que] Pedraza tiene prevenidas y ya empieza a ejecutar." ${ }^{88}$ Advertía sobre la crueldad de la Secretaría de Guerra y Marina al clamar que "prisiones, asesinatos, injusticias, violencias de todo género manchan ya las páginas de su historia". Al mismo tiempo, introducía voces y exclamaciones de alarma: "ATENCIÓN, ATENCIÓN, ATENCIÓN"49 o "los truenos pronostican erupción. Alerta! Alerta!”.50

Paralelamente a los llamados desesperados, el Correo demandaba la intervención de los valerosos patriotas. Además de que aseguraba que aunque el pueblo oaxaqueño había sido oprimido, el pueblo mexicano no había sido vencido por el malvado tirano. ${ }^{51}$ Publicaba comunicados, aparentemente escritos por ciudadanos, en donde patriotas oaxaqueños hacían un llamado de auxilio a los pueblos y a todas las autoridades, antes de que quedaran ahogados por la fuerza de "las cadenas"..$^{2}$ Prevenía: "los mexicanos dignos de este nombre deben prepararse para defender sus instituciones si se les ataca con el Plan de Tulancingo y Tratados de Córdova". ${ }^{3}$ Clamaba: "Patriotas: salvar la revolución libertadora!" 54

Después de la elección presidencial, en septiembre, los yorkinos no disminuyeron recriminaciones y otros ataques verbales iniciados durante la campaña. De manera significativa, ni siquiera cambiaron la discursiva al conocer de forma

${ }^{46}$ Correo, "Editorial", agosto 22, 1828.

47 Correo, "Editorial”, agosto 14, 1828; Correo, “Editorial”, agosto 21, 1828 y Correo, "Editorial", septiembre 09, 1828.

${ }^{48}$ Correo, "Editorial", septiembre 19, 1828.

49 Correo, "Editorial”, agosto 09, 1828.

${ }^{50}$ Correo, "Comunicados", agosto 30, 1828.

${ }^{51}$ Correo, "Editorial”, septiembre 01, 1828.

${ }^{2}$ Correo, "Comunicados”, agosto 17, 1828.

53 Correo, "Editorial”, septiembre 03, 1828.

54 Correo, “Editorial”, agosto 12, 1828. 
extraoficial la victoria pedracista en las urnas. Prolongaron la crítica diaria acerca de las medidas tomadas por la secretaría y siguieron con los mismos argumentos sobre los peligros de una administración pedracista. Con unas ligeras variaciones, mantuvieron de forma vigente, y recurrente, ambos aspectos durante los levantamientos concatenados desde Perote en septiembre a la Acordada en noviembre.

El Correo declaraba la inminencia de una revolución armada preparada por los pedracistas desde la Secretaría de Guerra y Marina y preguntaba: “¿No deberá temerse que abusando como hasta hoy ha abusado del ejército, forme una revolución si la cree necesaria para conseguir sus miras?" 55 Al llegar múltiples rumores de la revuelta santannista en Perote, de forma contradictoria, los editores yorkinos insertaban la proclama santannista y, dos tirajes después, negaban la existencia de una revolución. Restaban importancia a esta noticia y aseguraban que "nadie cree en sublevaciones en México". Señalaban que, por el contrario, Pedraza iba a usar estas patrañas para desplegar una acción "marcial", como en la ensangrentada Oaxaca, "que comprometa la tranquilidad" nacional y que mueva a "escenas de horror". ${ }^{56} \mathrm{Al}$ resultar indiscutibles los rumores, enmudecieron y, unas semanas después, informaron nuevamente de la asonada mediante una nota mínima y manifestaron que la Secretaría de Guerra y Marina actuaría con la usual prontitud para apagar la revuelta. ${ }^{57}$ No obstante, no demoraron en mencionar a los lectores la posibilidad de otorgar las facultades extraordinarias a la presidencia, y pronosticaron que Pedraza las solicitaría para terminar de subyugar a los mexicanos. ${ }^{58}$ Naturalmente, al demandar la presidencia tales facultades para sofocar la rebelión de Perote y nuevos brotes rebeldes, los yorkinos vieron corroborados sus augurios. Los editores yorkinos continuaron en octubre y noviembre con la nota de alarma sobre la tiranía pedracista al recalcar la "cacería” que Pedraza había emprendido contra yorkinos y aliados. Buscaron sustentar esta argumentación con dos eventos recientes:

\footnotetext{
55 Correo, "Editorial2, septiembre 04, 1828.

56 Correo, “Editorial”, septiembre 14, 1828.

57 Correo, “Editorial”, septiembre 25, 1828.

${ }^{58}$ Correo, “Editorial”, septiembre 26, 1828.
} 
la persecución de los pronunciados en Perote, y la formación de causa a Zavala.

Zavala, gobernador del Estado de México, representaba una figura líder entre los yorkinos radicales y en la campaña presidencial de Guerrero. Después de la victoria pedracista en las urnas, la atención general estaba dirigida a la reacción de Zavala. Este personaje mantendría una postura ambivalente. Acusaría a varios dirigentes militares yorkinos de planear una sublevación pro-guerrerista y, al mismo tiempo, tendría encuentros con numerosos individuos sospechosos de complicidad o abiertamente insurrectos. ${ }^{59} \mathrm{El} 17$ de septiembre, la asamblea federal ordenaría la persecución de los pronunciados en Perote y probables cómplices. Desde la Secretaría de Relaciones Interiores y Exteriores, Juan de Dios Cañedo, y la senaduría, Pablo Franco Coronel, acusaron formalmente a Zavala de apoyar a Santa Anna. El 5 de octubre, la senaduría aprobaría la aprehensión de Zavala y la Secretaría de Guerra y Marina enviaría una fuerza para arrestarle. Tal medida no resultaría complicada, ya que la senaduría tenía una mayoría escocesa e imparcial y la administración federal una mayoría imparcial. No obstante, la influencia de Zavala en el Estado de México permitiría que éste escapara. Desde la perspectiva de la prensa yorkina, la movilización de ambos grupos anti-yorkinos proporcionaba nueva y clara evidencia de la futura persecución pedracista contra yorkinos y aliados.$^{60}$ La pintura ofrecida por la prensa yorkina reafirmaba la cacería encarnizada contra eminentes patriotas, y presentaba a Santa Anna y Zavala como las primeras víctimas de una nueva y terrible vendetta que se generalizaría.

En resumen, los yorkinos basaron su idea de la opresión pedracista en tres principales argumentos. 1) La actitud anti-patriótica de Pedraza. Procuraron demostrar esta conducta al presentar la historia política de Pedraza y la relación, supuesta y real, de Pedraza con grupos enemigos de la patria desde la época de la lucha independentista hasta la administración Victoria. 2) La amenaza que esta actitud anti-patriótica representaba para la independencia y la república federal. 3) La tiranía de Pedraza. Solamente después de fortificar la idea de la postura anti-patriota de Pedraza, los yorkinos pudieron cimentar la noción de

59 Zavala (1845, II, p. 97).

${ }^{60}$ Correo, “Editorial”, septiembre 02, 1828. 
la opresión pedracista. Entonces, proporcionaron numerosos ejemplos de la persecución y la represión de la Secretaría de Guerra y Marina durante la administración Victoria, primordialmente aquellos relacionados a yorkinos y aliados durante los procesos electorales de 1828.

A pesar de clamores alarmantes de múltiples escenas de sangre en donde los yorkinos aseguraron mil fallecidos a causa de la Secretaría de Guerra y Marina, la evidencia mostraría una panorámica distinta a tal discursiva. Durante la contienda electoral, esta secretaría actuaría de forma moderada. Pedraza mantendría la senda legal, ya que evitaría una formación de causa que le dejara fuera de la presidencia. Posteriormente, frente a las rebeliones pro-yorkinas de la época post-electoral, Pedraza reaccionaría con mesura por los límites impuestos desde la presidencia y la cámara baja. Zavala y Tornel declararían posteriormente que la administración Victoria tenía fuertes limitaciones frente a las asonadas, y que Pedraza tenía las manos atadas por los otros poderes. ${ }^{61} \mathrm{De}$ manera que evidentemente la opresión pedracista clamada por los yorkinos sería una acusación orientada a una campaña de desprestigio contra Pedraza a causa de la disputa por la futura presidencia. Aunque, ciertamente, la posición dual de Pedraza, protagonista de la contienda presidencial y la Secretaría, facilitaría la controversia sobre qué había detrás de cada acción de la Secretaría de Guerra y Marina, i.e. intereses personales o nacionales.

\section{¿Qué debían de hacer los mexicanos contra la opresión pedracista?}

Tras la permanencia de la rebelión santannista y otros pequeños brotes, en octubre la prensa yorkina desplegaba una mayor osadía al aproximarse la fecha para cerrar las sesiones en los congresos federales. De manera puntual, citaba la sección dedicada a las guerras civiles en la obra Derecho de gentes y principios de la ley natural aplicados a la conducta y a los asuntos de las naciones y de los soberanos de Emer de Vattel para explicar al gobierno la actitud que debía de adoptar con los sublevados para apaciguar las revueltas. Llamaba a la autoridad federal a la clemencia y recomendaba buscar la negociación y “dar

\footnotetext{
${ }^{61}$ Zavala (1845, II, p. 94, 95 y 98, 99) y Tornel (1985, p. 386).
} 
satisfacción a los pueblos". Explicaba que el gobierno tenía que actuar con moderación y "tomar medidas suaves" que no irritaran "las pasiones" y causaran que los pueblos acudieran a "providencias desesperadas" (ultima ratio regum) al encontrarse en la alternativa penosa de defenderse y perecer antes que perder la honorabilidad y la vida en los cadalsos. ${ }^{62}$ Advertía que desafortunadamente las medidas sanguinarias de la autoridad federal imposibilitaban la concordia e incitaban a la revolución. ${ }^{63}$ Declaraba: "el gobierno está muy expuesto a no apagar sino fomentar el incendio, porque muchas veces no se calcula cuánto puede producir una chispa que se arroja sin previsión aunque con un objeto sano." ${ }^{4}$ Consideraba que cuando los gobernantes "adopta[n] providencias desesperadas, cuando se propone[n] desnaturalizar sus bases fundamentales porque juzga[n] que éstas se oponen a [...] la tranquilidad pública o a la consecución de sus fines, debe[n] detenerse en los medios [y marcarse límites, ya que] separándose de ellos [...] quedan disueltos los vínculos que nos ligaban a la magistratura." ${ }^{\circ}$

Los editoriales se tornaban más y más amenazadores. Informaban que el pueblo entero estaba desolado y listo para elevar una protesta violenta. Amenazaban: "el pueblo sufre con paciencia, hasta que cansado de ser oprimido, uniforma su opinión, y cual torrente que se despeña por la falda de una montaña, imposible de contener grita de voz en cuello: no más déspotas, no más tiranos." ${ }^{\prime 66}$ Advertían: "teman, pues, la venganza de los pueblos, que aunque tarda, siempre es segura, y teman la fuerza de la opinión, más terrible aún que la de las mismas leyes." ${ }^{67}$ Tales amonestaciones estaban acompañadas por una misiva ciudadana firmada por El Tolerante. La carta explicaba de forma resumida la penosa posición de los mexicanos. Apuntaba que la victoria escocesa-española, cristalizada en los resultados de la elección presidencial, había sembrado la discordia entre los mexicanos, y había abierto las puertas a una guerra fratricida. Interpelaba a Victoria a escuchar a la nación y liberarla de Pedraza al retirarle de la secre-

\footnotetext{
62 Correo, "Editorial”, octubre 11, 1828.

63 Correo, “Noticias Nacionales”, octubre 14, 1828.

64 Correo, “Editorial”, octubre 19, 1828.

65 Correo, "Editorial, octubre 03, 1828.

${ }^{66}$ Correo, "Editorial”, octubre 14, 1828.

67 Correo, "Editorial”, noviembre 01, 1828.
} 
taría, ya que los abusos autoritarios de este déspota indicaban, hasta a la inteligencia más rastrera, qué medidas debía de tomar el gobierno, si no para desaparecerlos, al menos para amortizar los terribles efectos. Sentenciaba:

Una lenidad e indulgencia que raya en criminal, es la sola que ha podido contener el golpe contra Pedraza; mas ahora es imposible evitarlo, la nación lo reclama, ella no quiere ver por más tiempo delincuentes presidiendo sus destinos, quiere que sea colocada la virtud y el mérito en los puestos eminentes. Está cansada de sufrir. Obedézcase su voluntad soberana, porque si no, el día de los cargos será terrible. ${ }^{68}$

Al mismo tiempo, los editores yorkinos sostenían que la legislatura veracruzana tenía la responsabilidad de provocar la protesta de Perote. Decían que la legislatura no había escuchado a la voluntad soberana al sufragar a Pedraza. Aprovechaban para vincular la inconformidad veracruzana a la nacional y, de forma paralela, plantear nuevamente la cuestión de las posibilidades existentes para una nación oprimida por una autoridad arbitraria.

La mayor desgracia de una nación es cuando sus elecciones son tan erradas que recaen en hombres indignos de desempeñar los poderes que reciben de los pueblos. Cuando llega esta calamidad, es preciso observar una total resignación hasta que pase el periodo constitucional para el que han sido electos, pero si la patria peligra porque los apoderados sean decididos adictos a nuestros antiguos opresores por su conducta versátil y escandalosa, por su obstinación en seguir solamente el camino de la venganza y no el de la pública opinión, y cuando solo se dedican a causar males infinitos a sus poderantes, entonces, entonces sí, tienen los pueblos un derecho incuestionable para arrojarlos sin demora alguna de los puestos que no son dignos de ocupar por más tiempo. ${ }^{69}$

\footnotetext{
${ }^{68}$ Correo, "Noticias Nacionales", octubre 21, 1828.

69 Correo, "Editorial”, octubre 09, 1828.
} 
Con estas palabras, los editores exhortaban a los buenos patriotas a rescatar a la nación de los enemigos de ésta, y apelaban al derecho natural para legitimar la ruptura con una autoridad refractaria.

Pocos meses después, Zavala repetiría la misma argumentación que la prensa yorkina al rememorar las motivaciones detrás de la rebelión de la Acordada..$^{70}$ En el Manifiesto del gobernador del Estado de México, declaraba que Pedraza había adoptado de forma sistemática una conducta represiva con la que esperaba eliminar a los descontentos, mientras, había "una voz, un grito universal [que] se oía por todas partes contra la conducta de [la Secretaría de Guerra y Marina;] se declamaba contra la tolerancia del presidente; pero se tronaba contra el sistema de opresión adoptado por sus ministros." ${ }^{71}$ Aseguraba que había deseado que Pedraza frenara la persecución emprendida, pero que había resultado vana esta esperanza. ${ }^{72}$ Por lo que, apuntaba Zavala, ante la tiranía desplegada por la autoridad federal, resolvería “usar del derecho sagrado, aunque peligroso, de la insurrección, al que apelan los pueblos como el último recurso a los males públicos" ${ }^{73}$

Pero ¿qué querían decir estos yorkinos al declarar una ruptura con una autoridad opresora e invocar el derecho de insurrección?

La resistencia contra la tiranía es una temática central en la literatura política. Filósofos antiguos y modernos abordaron de forma recurrente la relación de poder entre sociedad y autoridad gubernativa. Tras las revoluciones ilustradas en Europa y América, políticos y publicistas reconsideraron desde nuevos ángulos los principios de la sujeción al rey. En los territorios independientes de América, el derecho de insurrección representaría una temática substancial para la construcción nacional, especialmente en los términos de legitimidad de los nuevos gobiernos. Los políticos mexicanos de forma explícita decidieron no

70 Zavala negaría toda relación con la rebelión de Perote. Aseguraría que se uniría a los rebeldes yorkinos en la capital solamente después de presenciar los abusos de la administración Victoria, como la orden de apresarle, no antes. Al mismo tiempo, Tornel y Rivera harían referencia a la severidad excesiva de Pedraza con los rebeldes de Perote para justificar la resistencia yorkina. Zavala (1845, II, p. 90); Tornel (1985, p. 344) y Rivera (1873, II, p. 165).

${ }^{71}$ Zavala (1845, II, p. 85, 86).

72 Zavala (1845, II, p. 65).

73 Zavala (1845, II, p. 89, 90). 
mencionar el derecho de insurrección en la constitución de 1824, ya que tácitamente aceptaron esta figura al estar íntimamente ligada al derecho natural. ${ }^{74}$ No obstante, posteriormente enfrentaron numerosas problemáticas para delimitar las circunstancias en que la sublevación contra una autoridad constituida resultaba permitida, pues mantuvieron latentes los principios libertarios de la declaración independentista y, al mismo tiempo, buscaron fortificar la nueva gobernabilidad. Reconocieron que, ya que esta solución representaba una forma extrema, que sería peligrosa y horrenda al usarse cual medida ordinaria, debía de ser el último recurso de una nación oprimida. ${ }^{75}$

Los autores yorkinos ofrecieron durante varios meses ejemplos de la opresión pedracista antes de apelar al derecho de insurrección. Al invocar tal prerrogativa, no reflexionaron explícitamente de manera pública sobre tal derecho. Es posible que actuaron de esta forma por dos motivos. Consideraron que los mexicanos conocían los principios de la doctrina insurreccionista, ya que en discusiones anteriores los políticos los abordaron -especialmente después de la revuelta montañista, en donde los distintos grupos debatieron sobre la legitimidad de ésta y el papel de la doctrina en la incipiente nación-. ${ }^{76}$ Discurrieron que, ya que todo derecho natural es inviolable, solamente necesitaban demostrar la transgresión contra éste para justificar una resistencia. No obstante, en breves menciones explícitas sobre el derecho de insurrección, ofrecieron las herramientas necesarias para descifrar su postura.

74 A pesar del amplio espectro de perspectivas insurreccionistas, la historiografía mexicanista que aborda el derecho de insurrección al estudiar la época decimonónica presenta dos posturas opuestas. Una interpretación se enfoca en los fundamentos de la escuela tomista, especialmente la neo-escolástica. Véase Stoetzer (1979, p. 123). Otra interpretación resalta la influencia liberal y la herencia francesa de las dos declaraciones de los derechos humanos del siglo dieciocho. Véase Andrews (2004, p. 143-170).

75 El Oriente, “Remitido”, enero 06, 1828.

${ }^{76}$ La rebelión escocesa también atacaría de forma directa a Pedraza, a más de que denunciaría la opresión de la Secretaría de Guerra y Marina. No obstante, esta asonada se distinguiría de la yorkina en tres características principales: sería dirigida por una fuerza armada raquítica con una influencia política en decadencia, tendría una existencia breve al resultar suprimida rápidamente, y argumentaría usar el derecho de petición y no amenazaría a la autoridad federal con una ruptura. 
Los autores yorkinos citaron y discutieron a dos autoridades fundamentales en el derecho de gentes, i.e. Vattel y una lectura puntual de éste sobre ciertas ideas de Hugo de Groot, para interpretar en la prensa el derecho de insurrección. ${ }^{77}$ De manera que podemos considerar que los autores yorkinos declararon a Vattel su principal pauta teórica. Esta referencia no sería baladí. Durante los siglos xviII y xix, Derecho de gentes de Vattel representaría un libro de texto indispensable para estudiantes de leyes y la guía imprescindible en derecho internacional para gobernantes, diplomáticos y políticos. Primordialmente para aquellos pertenecientes a naciones germinales que buscaban establecer una legitimidad, ya que reuniría de manera precisa los principales argumentos en derecho natural para defender la independencia y la soberanía de las prístinas naciones. De esta manera, colocaría a las últimas en una posición de legalidad, igualdad y protección frente a otras, especialmente aquellas más poderosas. A más de que orientaría en la solución de problemáticas intestinas.

Los estudiosos del derecho de insurrección evidenciaron una interpretación y una sistematización distintiva al abordar esta doctrina. Presentaron enfoques diferentes, ya que enfatizaron unos aspectos y omitieron otros según la coyuntura histórica y la intención personal. No obstante, igualmente, destacaron de forma recurrente unos mismos aspectos. De esta manera, formularon unos requerimientos para apelar al derecho de insurrección. La justificación ofrecida por rebeldes y autores yorkinos seguiría unas líneas similares a estos elementos indispensables, mismos que formaron parte de la doctrina insurreccionista de Derecho de gentes. 1) la causa debe de ser justa. La autoridad debe de resistirse porque es ilegítima (de forma inicial o por inmoralidad o abuso de poder). 2) La causa debe de ser necesaria. La opresión es insufrible e irremediable por los medios ordinarios, ya sean legales o políticos. 3) Existe evidencia de los abusos. 4) Resulta infructuosa toda intención de negociación con la autoridad, la cual no tiene clemencia, moderación o deseos de apaciguar a los descontentos. 5) La mayoría de la nación respalda la resistencia armada. 6) Los males producidos por la revolución no deben de ser mayores que aquellos causados por la

77 Véase Correo, "Editorial”, octubre 11, 1828. También Correo, "Comunicados", Spes in Livo, diciembre 27, 1826. 
opresión. 7) Existe una alta probabilidad de triunfar. 8) La victoria debe de resolver los males provocados por la tiranía. ${ }^{78}$

La prensa yorkina buscaría demostrar que la nación sufría las condiciones necesarias para una guerra justa. No cuestionaría de manera directa principios, leyes e instituciones que fundamentaban la constitución y la gobernabilidad establecida en $1824 .{ }^{79}$ No obstante, buscaría relacionar las circunstancias insufribles de 1828 y 1820 -en referencia al Plan de Iguala que declararía la independencia de España-. ${ }^{80} \mathrm{Al}$ igual, Zavala compararía la rebelión de la Acordada y la rebelión veracruzana de Santa Anna en 1822 -la que contribuiría a eliminar la monarquía iturbidista y fundar la república-. ${ }^{81}$ Ambos eventos históricos desafiaron a las autoridades consideradas tiranas, representaron trasformaciones políticas categóricas y fueron considerados legítimos por una mayoría (de la élite política). De manera que los yorkinos trazaron esta relación para mostrar una igualdad de condiciones: la situación alarmante de la nación ante la tiranía, la necesidad de una solución rupturista extrema frente a la autoridad, y la legitimidad de la insurrección al resultar apoyada por una mayoría.

Los yorkinos se enfocaron en la tiranía de Pedraza al apelar al derecho de insurrección contra la autoridad federal. Trazaron una línea argumentativa orientada a dar evidencia de la opresión pedracista para justificar la resistencia a una potestad que consideraron ya ilegítima. Primeramente, explicaron la transformación de su antigua postura pro-pedracista al asegurar que tal reconsideración respondía a la mutación de Pedraza. Pedraza ya no representaba una figura patriótica. Si una autoridad trabajaba para alcanzar beneficios personales, en lugar de beneficios comunes, no respondía a la patria y debía de apartarse de la labor gubernativa. Pedraza usaba la secretaría para apoyar a amigos y

${ }^{78}$ Unos autores fueron explícitos de manera extrema, en todos o algunos aspectos, mientras que otros autores no fueron explícitos. A diferencia de Vattel, los yorkinos prefirieron explicar los elementos insurreccionistas con ejemplificaciones de acontecimientos pasados o actuales, o breves menciones. Esta secuencia puntual y resumida de Vattel tiene la finalidad de proporcionar una mayor claridad a la doctrina del derecho de insurrección y su relación con la perspectiva insurreccionista yorkina.

79 Correo, “Editorial”, septiembre 03, 1828.

80 Correo, “Editorial”, septiembre 09, 1828.

81 Zavala (1845, II, p. 94). 
atacar enemigos y, al igual, para asegurar la futura presidencia, e.g. removía de los puestos gubernamentales a ciudadanos patrióticos para remplazarlos por aliados. A más de que negaba a las víctimas toda posibilidad de clemencia, negociación o moderación. Los yorkinos agregaron una prueba más de la actitud anti-patriótica de Pedraza al argumentar que éste apoyaba a los opositores de la libertad mexicana. Aseguraron que Pedraza trabajaba por la disolución de la independencia, ya que nuevamente mantenía una alianza con españoles y, al mismo tiempo, con escoceses (todos relacionados a los eventos contrarios a la libertad nacional). Declararon que Pedraza atacaba los fundamentos de la república federal, ya que quería instaurar una potestad absolutista, ya fuera una dictadura o una monarquía. De esta forma, los yorkinos buscaban demostrar que Pedraza violaba de forma cotidiana las leyes establecidas para acomodarlas a objetivos propios y así encaminaba la nación a la ingobernabilidad, la disolución social, y la más espantosa posibilidad: la pérdida de la independencia. Pedraza ya no actuaba de forma patriótica, sino tiránica. Indudablemente, discurrían, las distintas pruebas demostraban que la situación resultaba insostenible para el pueblo mexicano. En esta circunstancia, todo mal gobierno debía de ser remplazado y el derecho de insurrección justificado. Los yorkinos resolvían que no había duda de que contaban con la fuerza para alcanzar la victoria, pues representaban la mayoría de la nación y eran apoyados por la voluntad general. La pregunta final sería: ċla revuelta pro-yorkina resolvería la opresión y tendría unos beneficios mayores que la eliminación de Pedraza de la secretaría y de la futura presidencia? La respuesta de los yorkinos estaría plasmada en sus numerosas promesas y sería afirmativa, ya que los patriotas, como Guerrero, gobernarían, y México recuperaría la libertad..$^{82}$

Una parte substancial de la mayoría de las teorías insurreccionistas sería aquella que prevenía actuar con ligereza al iniciar una sublevación. Los insubordinados debían de demostrar que acudieron a la solución última después de agotar todos los intentos posibles de negociación con la autoridad, y mostrar que ésta no había sido sensata y los había orillado a la guerra. Los yorkinos sostuvieron que la autoridad no tenía, o no quería brindar, los medios para dar

${ }^{82}$ Correo, “Editorial”, diciembre 09, 1828. 
una solución. Al igual que Vattel, citaron abiertamente un pasaje memorable de Groot que acentúa la responsabilidad de la autoridad gubernativa en no incitar a una rebelión armada y calmar al pueblo. Derecho de gentes de forma repetida alentaría al gobierno a actuar con "clemencia" y "prudencia" frente a los insurrectos. ${ }^{83} \mathrm{Al}$ mismo tiempo, aconsejaría la amnistía para preservar la paz y salvar la sujeción política pactada. ${ }^{84}$ Aseguraría: "la negación o delación del gobernante en proporcionar justicia, puede sola ser una excusa para los transportes furiosos del pueblo cuya paciencia ha quedado exhausta -e inclusive justificarlos, si los males son intolerables y la opresión enorme y manifiesta-."85 De manera similar, la prensa yorkina llamaría a la autoridad federal a que actuara con "clemencia” y moderación, que otorgara una amnistía a Santa Anna y Zavala, y que se cuidara de no provocar la furia popular. Igualmente, Zavala aludiría a la falta de conmiseración y "prudencia” de Pedraza para justificar la revuelta de la Acordada y ataque al Parián. ${ }^{86}$ Los yorkinos argumentaron que evitaron levantarse hasta el último momento, no obstante, frente a la sinrazón de Pedraza, no tuvieron otra salida que la ley última, la auto-preservación (individual y social), según las palabras de Vattel, y responsabilizaron al gobierno federal de las consecuencias. ${ }^{87}$

Desde la contienda presidencial, los autores yorkinos ofrecieron numerosas pruebas de la conducta tiránica de Pedraza para demostrar que peleaban una guerra justa y necesaria. Así, la justificación yorkina expondría ejemplos concretos - relacionados a los requisitos recopilados en Derecho de gentes-, antes que discusiones doctrinales para legitimar el derecho de insurrección. No obstante, ciertamente, la justificación yorkina no estaría basada en una perfecta correlación entre los requisitos en la teoría insurreccionista de Vattel y pruebas, sino que igualmente integraría distintas concepciones políticas subyacentes en la cultura política mexicana y yorkina. De manera que la justificación yorkina conformaría una red conceptual re-articulada a la luz electoral -que acentuaría,

\footnotetext{
83 Vattel (2008, Book III, Ch. VIII, § 290).

84 Vattel (2008, Book III, Ch. VIII, § 291).

85 Vattel (2008, Book III, Ch. vIII, § 290).

86 Zavala (1845, II, p. 65 y 84 ).

87 Zavala (1845, II, p. 96, 97, y 110).
} 
re-significaría, borraría e importaría diferentes nociones-, la cual incluiría a Vattel o no. Esta red conceptual relacionaría determinadas interpretaciones que, desde una perspectiva individualista y comunitaria, respaldarían y darían personalidad propia a la teoría insurreccionista yorkina. ¿De qué manera esta red estaría articulada?

La justificación yorkina a la rebelión de la Acordada partiría de una relación fundamental en las teorías contractualistas: la sujeción política (pactum subjectionis). Esta noción considera que la sociedad organizada consiente de forma voluntaria depositar la autoridad gubernativa en una persona o agrupación para que ejerza con principios de justicia y bienestar. Distintas vertientes confluyeron en esta idea de la sujeción política. 1) La concepción republicana clásica de una sociedad corporativa fundamentada en el bien común -en Grecia (to koinei sympheron) y en Roma (bunum commune)-. 2) La concepción escolástica que integra la perspectiva comunitaria judeocristiana primigenia y una reinterpretación de la noción republicana clásica. 3) La perspectiva moderna, en donde diferentes autores retoman la noción republicana clásica y conciben una nueva idea de individuos libres unidos racionalmente en comunidad para la felicidad y la defensa de la libertad conjunta y propia. ${ }^{88}$ Desde esta última perspectiva, Vattel explicaba que los individuos forman una sociedad política solamente con la finalidad de su "preservación, seguridad, felicidad y perfección". 89

Numerosas teorías contractualistas señalaban que la sociedad puede presentar resistencia a la autoridad si ésta no sigue principios de justicia y bienestar, i.e. si no trabaja para la felicidad general (el bien común) y ejerce mal gobierno. Explicaban que cuando el gobierno se desempeña de forma injusta y busca bienestar personal, en lugar de general, el gobierno rompe el pacto y entonces se constituye en tiránico y la sociedad queda libre de la sujeción política. De esta manera, la soberanía retorna a la sociedad. ${ }^{\circ}$ Vattel decía: "la autoridad soberana es establecida únicamente para el bien común de los ciudadanos." "Un buen gobernante, debe de tener presente que la autoridad soberana no le es confiada para buscar la propia satisfacción o ventajas privadas y que debe orien-

\footnotetext{
${ }^{88}$ Weinstock y Nadeau (2004).

89 Vattel (2008, Book I, Ch. III, § 28).

90 Véase Locke (1937).
} 
tar todas sus miras, todos sus pasos, a la grandeza del Estado y el pueblo sometido a él". ${ }^{91} \mathrm{Si}$ la autoridad del gobernante es otorgada, limitada y regulada por las leyes fundamentales, al abusarlas, el gobernante falta a las mismas leyes que le constituyeron como soberano, rompe los lazos contractuales y en adelante ejerce fuera de un título justo y se transforma en usurpador y opresor: la nación queda libre, luego la nación no está obligada a obedecerle y puede resistirle. Si la sociedad y el gobernante se unieron con una constitución para la felicidad común, al no guardar éste la constitución y, principalmente, la finalidad de la unión, la unión queda destruida. ${ }^{92}$

Los políticos decimonónicos mexicanos reflexionaron de forma repetida sobre las teorías contractualistas, pues dos cambios trascendentales -la declaración de independencia y la instauración de la república- fueron efectuados con los argumentos de luchar para el bien común al eliminar el mal gobierno y entrar en un nuevo pacto. ${ }^{93} \mathrm{Al}$ analizar la relación contractual entre la sociedad y la autoridad gubernativa, estos políticos convivieron con distintas tendencias plasmadas en: textos clásicos de autores particulares o códigos legales, relaciones feudales hispanas, escritos escolásticos, además de obras modernas acreditadas u obras que tradujeron, discutieron y difundieron estas obras. ${ }^{94}$ Los yorkinos conocieron múltiples vertientes. Aunque hicieron referencias bíblicas (una metodología concurrida entre escolásticos y modernos), no evidenciaron una inclinación por la lectura tomista, sino que favorecieron la republicana clásica y la moderna. El yorkino Luis Espino, importante folletista de la tendencia radical, en diciembre de 1826 citaba directamente a Vattel al explicar la ruptura de la sujeción política, y concluía: "la nación puede sustraerse de la obediencia si las autoridades designadas rompen el código, porque solamente al Ser Eterno se le debe obediencia”. ${ }^{55}$ Probablemente, Zavala apoyaba una idea de la sujeción política basada en nociones republicanas clásicas y liberales, ya

\footnotetext{
${ }^{91}$ Vattel (2008, Book I, Ch. IV, § 39).

$9^{2}$ Vattel (2008, Book I, Ch. IV, § 51).

93 Guerra (2000, p. 15).

94 Véase Ramos (1943, p. 68), Herrejón (1983, p. 42, 43), Chiaramonte (2004, p. 567) y Kern (1939).

95 Correo, "Comunicados", Spes in Livo, diciembre 27, 1826. Véase Correo, "Variedades", mayo $05,1828$.
} 
que tenía en una gran estima a Cicerón y Locke, y no tenía simpatía alguna por las escolásticas. ${ }^{96}$ De la misma forma, en la sección previa observamos que la prensa yorkina sostenía perspectivas análogas -parecidas a aquellas de Vattelal respaldar la rebelión de la Acordada.

La justificación yorkina a la rebelión de la Acordada estaría cimentada en una perspectiva iusnaturalista. Las teorías de derecho natural sostienen que los individuos tienen ciertos derechos originados en la naturaleza humana. Estos derechos son eternos, universales, superiores e independientes a derechos positivos y consuetudinarios. Desde la interpretación de Locke, los individuos no rendían todos los derechos de forma irrevocable a la autoridad gubernativa, sino que solamente cedían aquellos derechos orientados a preservar el orden y garantizar la protección de los derechos naturales. Los individuos retenían para sí mismos los otros derechos, i.e. los derechos a seguridad, libertad y propiedad, y podían reclamarlos, porque éstos eran naturales y, por tanto, inalienables. Locke subrayaba que cualquier autoridad debía ser resistida si atacaba estos derechos. Sin detenerse especialmente en las posibles excepciones, aseguraba que los individuos podían eliminar a la autoridad y apelar al derecho de insurrección en circunstancias extremas. En una primera instancia, si la autoridad violaba leyes fundamentales, particularmente la libertad, ya que, cuestionaba Locke, ¿quién dudaría que sería lícita la resistencia a la injusticia y la crueldad de una autoridad opresiva? En una segunda instancia, si la autoridad comprometía la estabilidad de la nación o amenazaba al Estado constituido. ${ }^{77}$ Preguntaba Locke: los ciudadanos "deberían ver sus ciudades saqueadas, y reducidas a cenizas, sus esposas e hijos expuestos a la avaricia y la furia de la tiranía, y [...] reducidos por ésta a la ruina y todas las miserias de la opresión, y todavía no inmutarse?"98

En la sección previa, establecimos que los escritores yorkinos clamaban que Pedraza atacaba los principios esenciales de todo ser humano: seguridad, libertad y propiedad. Declaraban que la Secretaría de Guerra y Marina había destruido, perseguido y apresado, en otras palabras, restringido los derechos

\footnotetext{
96 Zavala (1845, I, p. 32, 33, y II, p. 281-299 [“Conclusión”]).

97 Locke (1980, § 237). Cf. Thomas Jefferson, véase Mirkin (1972, p. 62).

98 Locke (1980, § 233).
} 
naturales de los ciudadanos patriotas, e.g. los vinagres, Santa Anna y Zavala. Los yorkinos presentaron una descripción pormenorizada de las diferentes maneras en que la opresión pedracista había privado a los mexicanos de derechos fundamentales. Refirieron los ataques repetidos a la vida de los ciudadanos, a más de la libertad, la estabilidad y la propiedad nacional. Expusieron lecturas y ejemplos concretos que tenían una significativa semejanza con la perspectiva liberal de Locke y documentos inspirados en ideas lockeanas -e.g. la declaración de independencia de los Estados Unidos de América (1776), y la declaración de derechos humanos (1789 y 1793)-. ${ }^{99} \mathrm{Al}$ igual que Locke, la prensa yorkina y los pronunciados contra Pedraza presentaron una imagen de desesperación por "la propia conservación”, y obligación ciudadana en la defensa de libertades fundamentales naturales para justificar la revuelta. ${ }^{100}$ Vattel seguiría la premisa de respaldar la resistencia para la auto-preservación con la misma tonalidad que Locke. No obstante, de la misma forma que la mayoría de los otros teóricos, ofrecería grandes obstáculos a la resistencia contra una autoridad que poseyera los medios constitucionales e institucionales para peticionar una solución a la injusticia. Así, fuertemente aconsejaría buscar otras alternativas a una sublevación, a diferencia de Locke. Recomendaría priorizar la estabilidad, actuar con prudencia y tolerar con paciencia los males soportables, ya que inclusive David había optado primero por esconderse de Saúl, antes que enfrentarle. ${ }^{101}$ La justificación yorkina inclinaría la balanza a la retención ciudadana de los derechos naturales y la insurrección por encima de la restricción. De esta forma, seguiría a Locke al ignorar los pasajes limitantes de Vattel y otros teóricos.

Anteriormente, observamos que Zavala y el Correo subrayaron que los yorkinos rebeldes representaban la potestad última: la soberanía popular. Usaron diferentes acepciones y combinaciones de éstas para destacar unidad en la indignación con la que los mexicanos demandaban la caída de Pedraza, las más frecuentes fueron: voluntad general o nacional, opinión publica, voz soberana, mayoría, los pueblos y el pueblo. Por una parte, verificaban una exigencia de la doctrina insurreccionista para justificar una revuelta: unanimidad. Por otra

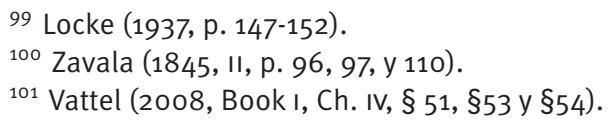


parte, enfatizaban la autoridad de la soberanía popular como la entidad que protestaba contra la potestad transgresora. En otras palabras, según los yorkinos, la demanda de terminar con la opresión pedracista no vendría de Santa Anna o Zavala, sino de la soberanía popular. La parte significativa de asegurar que esta última dirigía los reclamos radicaba en que, desde la perspectiva contractualista, "solamente como individuos la gente cedería esta autoridad para implementar leyes, pero en tanto una comunidad unida (universitas) todavía conservaría esta autoridad". ${ }^{102}$ Y podría reclamarla. Rousseau explicaba que los ciudadanos y la autoridad gubernativa estaban unidos mediante el Estado en una capacidad recíproca y, de esta forma, contaban con obligaciones y privilegios legitimados mediante consenso al contrato social y estaban sometidos todos a la voluntad general. ${ }^{103}$ Acertadamente, Shannon K. Brincat explica que "sería la operación de ambas premisas, consenso en la formación del Estado y obediencia a la voluntad general, la que uniría a todos, incluso el soberano [dentro del Estado]". ${ }^{104}$ De manera consecuente, en el momento en que el soberano dejara de actuar fuera de la voluntad general, el Estado quedaría disuelto y el contrato social roto. Los yorkinos clamaron que Pedraza y diferentes autoridades de la potestad federal no obedecían más la voz del pueblo (la voluntad general), luego, rompían el pacto, y el pueblo debía de actuar. Así, abrieron la caja de Pandora.

Las teorías insurreccionistas fueron muy cuidadosas al identificar quién, de manera específica, tenía la facultad de presentar resistencia a la tiranía. Con unas pocas excepciones -e.g. la interpretación escolástica hispana de Juan de Mariana que autorizaba a una figura heroica a tomar la iniciativa de envenenar al monarca-, de Aristóteles a Thomas Jefferson, escritores y políticos coincidieron en otorgar esta iniciativa a la élite política. ${ }^{105}$ De ninguna forma aprobarían que una persona o forma tumultuaria cualquiera hiciera suya esta prerrogativa. Vattel calificaba de "monstruosa" la idea de Mariana de que una persona

\footnotetext{
102 Skinner (1988, p. 394).

103 Rousseau (1950, Ch. VI y VII).

104 Brincat (2008, p. 228, 229).

105 Véase Ford (1985, p. 46); Aquinas (1957, caput vi) y Mirkin (1972, p. 67). Cf. Mariana (1854, II, Ch. vi, p. 482).
} 
privada iniciara, dirigiera o realizara una acción insurreccionista, y más una solución tiranicida. ${ }^{106}$ Señalaba que la nación, o la autoridad que la representa, puede reformar la constitución, "si la nación entera unánimemente está inclinada a esto. Pero, ¿qué pasa si la nación está dividida? [...] la opinión de la mayoría debe pasar sin disputa por la de toda la nación, de otra forma, sería casi imposible para la sociedad tomar una resolución”. ${ }^{107}$ Decía:

Si una nación está insatisfecha con la administración pública, podría aplicar los remedios necesarios, y reformarla. Pero obsérvese que digo 'la nación', ya que estoy lejos de la idea de autorizar a unos cuantos descontentos o incendiarios a perturbar a los gobernantes al incitar murmuraciones y sediciones. [...] no es asunto de un pequeño número de ciudadanos poner al Estado en peligro con la pretensión de reformarlo. ${ }^{108}$

Vattel concluía: "porque si unos ciudadanos juzgan injusta una medida, no hablan por todos" ${ }^{109}$ En Cartas escritas desde la montaña, Rousseau advertía de los peligros de que unos cuantos líderes con fines particulares buscaran erigirse en representantes de la voluntad general. Indicaba que "la mayoría de los conflictos intestinos en los Estados vienen de una estúpida y brutalizada población [...] alborotada de manera secreta por hábiles revoltosos con alguna autoridad que quieren extender" ${ }^{110}$

Para muchos políticos anti-yorkinos, la forma de intervención política señalada por Rousseau precisamente vendría a caracterizar la posición adoptada por la logia "popular”. Los yorkinos mantuvieron una discursiva pública inclinada hacia "el pueblo", la cual formaría una parte importante de su plataforma política. Al mismo tiempo, se auto-proclamaron voceros del pueblo mexicano. Esta postura dual apelaría a los sectores desprotegidos de la sociedad para atraerlos a la causa partidista y, al igual, validaría la representatividad y

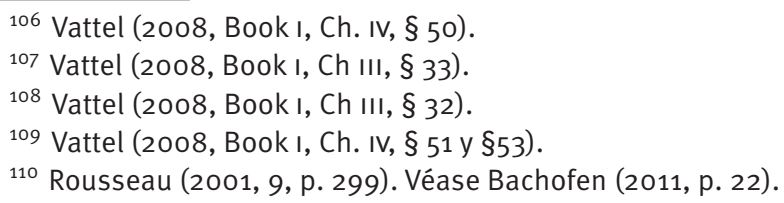


efectividad confrontativa de los yorkinos. De esta forma, los yorkinos mostraron reveladoras problemáticas en las diferentes perspectivas de la participación política y, así, generaron una significativa discusión sobre qué constituía "el pueblo": quiénes eran aquellas organizaciones o personalidades autorizadas para representarle y darle voz (ciudadanos, ayuntamientos, legislaturas federales o estatales, militares, partidos o reuniones de diferente índole). Los yorkinos apoyaron de forma creciente una radicalización en la inclusión política de "el pueblo" y atribuciones políticas, a más de una discursiva simpatizante de la democracia -una posición bastante progresiva en aquellos tiempos- como una de las piedras angulares de su personalidad partidista. Para ganar preponderancia, los yorkinos acentuaron de forma drástica esta postura durante la elección presidencial y la rebelión de la Acordada en 1828. Los yorkinos radicales subrayaron que la última y la única legitimidad gubernativa quedaba depositada en "el pueblo". En múltiples ocasiones, destacaron que artesanos, campesinos, soldados e "indios" eran "el pueblo", y éstos deseaban la presidencia para una persona con la que se identificaran, i.e. Guerrero. ${ }^{111} \mathrm{Al}$ mismo tiempo, apoyaron que "el pueblo" expresara esta voluntad de distintas maneras, en tiempos fuera de los procesos electorales, y en espacios fuera de los instituidos por la constitución. Así, al estallar la rebelión de la Acordada señalaron que pueblo, pueblos, soberanía, voluntad general o nacional, opinión pública, o mayoría clamaba contra Pedraza. Los yorkinos declararon que eran los representantes del pueblo y, naturalmente, asumieron que debían de actuar acordemente.

Aunque fueron los líderes de la Acordada los que lanzaron la revuelta, de forma previa, algunos de éstos y otros yorkinos buscaron legitimarla desde periódicos, cartas o manifiestos de ayuntamientos y milicias, además de reuniones tumultuarias. ${ }^{112}$ Validaron estas diferentes participaciones en sus distintos espacios al clamar que estos grupos representaban la voluntad general y, ya que desde esta perspectiva cualquiera podía iniciar una rebelión y ejercer el derecho de insurrección, abrieron la puerta a una forma ultra-democrática de participación política.

\footnotetext{
${ }^{111}$ Águila, "Editorial”, octubre 14, 1826 y Correo, "Comunicados", octubre 20, 1827.

${ }^{112}$ Correo, “Editorial”, febrero 03, 1828.
} 


\section{Consideraciones finales}

¿Los escritos yorkinos buscaron fomentar una sublevación? Ciertamente. Durante la administración Victoria, periódicos, folletos y papeles sueltos de todos los tintes políticos no solamente eran leídos de forma privada por mujeres y hombres de bien, sino que eran "gritados" y leídos públicamente en barberías, cafeterías, tabernas y portales para que las ideas se esparcieran entre "el pueblo bajo" y alentaran la concienciación o la participación política de éste. ${ }^{113}$ En los momentos álgidos de la elección presidencial de 1828, diferentes sectores pedracistas condenaron a las publicaciones yorkinas. Reclamaron los excesos en la libertad de imprenta y explicaron que sus textos incendiarios fomentaban desobediencia a la constitución y violencia pública. ${ }^{114}$ Redoblaron las acusaciones después de que en la capital hordas armadas alentadas por yorkinos salieran a la calle a protestar contra Pedraza e intentaran incendiar las imprentas anti-yorkinas. ${ }^{115}$ Pero ¿de qué manera específica fomentaron una sublevación? La campaña de desprestigio contra Pedraza, la invitación a salvar a la nación o la referencia a la salvaguardia insurreccionista fueron presentadas de forma diaria y profusa durante varios agitados meses, y así dieron una cotidianeidad y normalidad a reclamos y argumentos yorkinos y, al mismo tiempo, otorgaron a los lectores herramientas conceptuales e identitarias para la asimilación de esos argumentos.

¿De qué manera los yorkinos buscaron justificar y legitimar la insubordinación? Los autores yorkinos fundamentaron la campaña contra Pedraza en la supuesta actitud anti-patriótica de éste. En primera instancia, recordaron su pasado "vergonzoso", proporcionaron distintos argumentos para probar su vuelta a éste, y anunciaron la ruptura entre la logia y Pedraza a causa de tal actitud. En segunda instancia, declararon que una autoridad anti-patriótica no merecía la secretaría o la futura presidencia, ya que sería enemiga de la libertad nacional. Igualmente, los yorkinos presentaron dos aproximaciones diferentes

113 Águila, "Comunicados”, septiembre 29, 1826; Correo, “Comunicados”, mayo 03, 1827; y Sol, “Comunicados”, marzo 11 y $28,1828$.

114 Águila, “Editorial”, agosto 07, 1828.

115 Águila, “Comunicados”, septiembre 18, 1828.

ESTUDIOS DE HISTORIA MODERNA Y CONTEMPORÁNEA DE MÉXICO 55, enero-junio 2018, 77-119

DOI: http://dx.doi.org/10.22201/iih.24485004e.2018.55.63803 
para alentar y validar desde la prensa una insubordinación contra Pedraza. Por una parte, radicalizaron la discursiva popular y, por otra parte, realizaron una profusa ejemplificación de la supuesta personalidad tiránica de Pedraza para evidenciar la existencia de las condiciones necesarias de una guerra justa. Ambas aproximaciones urdieron los vínculos conceptuales que darían forma a su teoría insurreccionista. Sin embargo, debemos de recordar que la justificación insurreccionista constituiría una narrativa periodística, i.e. pública, con características propias. La movilización yorkina en la prensa no correspondería necesariamente a la movilización pro-yorkina en otros ámbitos, sino que formaría parte de múltiples engranajes creados para minar la autoridad gubernativa y electoral y, al mismo tiempo, apoyar la reacción ciudadana.

Escritores y rebeldes yorkinos no mencionaron frecuentemente sus múltiples fuentes para sustentar sus ideas políticas. No obstante, al abordar la doctrina insurreccionista, los autores yorkinos mencionaron de manera consistente a Vattel y proporcionaron los elementos suficientes para dilucidar aquellas concepciones que relacionaron a tal doctrina. Los yorkinos eligieron ciertas nociones puntuales con la finalidad de otorgar más potencia a la ciudadanía frente a la autoridad gubernativa. Así, concordaron con la idea de mayoría y la doctrina de la voluntad general de Rousseau para legitimar y otorgar fuerza ilimitada a la soberanía popular y su perspectiva de participación política. Por otro lado, manifestaron una interpretación contractualista con una inclinación moderna de la sujeción política. Citaron a Vattel para destacar la relación voluntaria y racional entre autoridad gubernativa y sociedad. Señalaron que una vez que la autoridad no tiene moderación, sino que gobierna de forma opresora -ataca los derechos esenciales- rompe los vínculos pactados y ya no debe de ser obedecida. Así, la soberanía retorna a la sociedad. Desde una concepción liberal, priorizaron la defensa de los derechos naturales. De la misma forma que Locke, y a diferencia de Vattel, se inclinaron enérgicamente hacia la limitación estatal y la prontitud a aceptar una sublevación de parte de la sociedad. En la rebelión de la Acordada todos estos principios confluyeron de forma vigorosa -a causa de la radicalización en la interpretación yorkina de la participación política popular durante la coyuntura electoral - y redefinieron espacios y tiempos de la intervención ciudadana. Estos principios, expresados por una logia 
(no regulada por la constitución), poderosa e insubordinada, a más de auto-proclamada representante del pueblo y la voluntad general, contribuyeron a la fractura de una endeble autoridad gubernativa con una legitimidad todavía en construcción. De esta manera, los yorkinos provocaron fuertes reacciones inmediatas. Los hechos relacionados a la elección presidencial alentaron a escoceses e imparciales a demandar una limitación constitucional a la participación política. ${ }^{116}$ Después de la rebelión de la Acordada, ambos grupos se fusionaron con nuevos aliados para legislar elecciones populares e insurrecciones. ${ }^{17}$

La noción insurreccionista yorkina obligaría a cuestionar la efectividad gubernativa de las instituciones establecidas con la república federal y la constitución. Al igual, reviviría miedos profundos de los mexicanos a una repetición de sangrientos episodios de las masas enardecidas durante las luchas independentistas o la revolución francesa. Por otro lado, contribuiría a dar una continuidad a la presencia legítima del derecho de insurrección en la cultura política del México decimonónico, ya que la victoria yorkina en la elección presidencial demostraría que esta noción sería una herramienta efectiva para acceder al poder. Consiguientemente, provocaría persistentes debates y revaluaciones. Unos sectores políticos defendieron conservar el derecho de insurrección como recurso necesario contra la tiranía. Otros personajes y grupos aconsejaron ser más cautos al interpretar el derecho de insurrección -incluidos algunos yorkinos radicales, e.g. Zavala-y manifestaron la necesidad de adoptar una posición más conservadora al demandarlo y llamar al pueblo a ejercerlo. ${ }^{118}$ La atención a esta temática escalaría y alcanzaría la asamblea legislativa federal, la cual discutiría reglamentar el derecho de petición y el derecho de insurrección al fraguar la constitución de $1836 .{ }^{119}$

La rebelión de la Acordada forzaría a replantear aquellas nociones y preocupaciones que fueron más relevantes para una nación en tiempos formativos, e.g. rebeliones (derecho de petición e insurrección), participación y

116 Véase Águila, “Editorial”, mayo 28, 1828; Sol, “Editorial”, mayo 23, 1828 y Correo, “Miscelánea”, junio 20, 1828.

${ }_{117}$ Véase Andrews (2004, p. 143-170).

${ }_{118}$ La Verdad Desnuda, n. 6, 1833 y Zavala (1845, I, p. 261).

119 Vid Noriega (1972, I, p. 115-153). 
representación política, soberanía, legitimidad, y distintos problemas de gobernabilidad. De esta manera, mostraría que los levantamientos armados no representaron solamente momentos de amenaza a la construcción nacional, sino de oportunidad para repensarla, crear disensos y consensos y, así, cimentarla. La rica literatura historiográfica generada sobre esta ruptura del orden legal necesita ser explorada en sus distintos aspectos. Al igual, ideas, referencias y prácticas manifiestas en la rebelión de la Acordada deben de ser comparadas y relacionadas a otras rebeliones armadas del México decimonónico, y diferentes interpretaciones de las teorías insurreccionistas.

\section{Fuentes}

Hemerografía

Águila Mejicana, México, 1826-1828.

Correo de la Federación Mexicana, México, 1826-1828.

El Oriente, México, 1828.

El Sol, México, 1828.

La Verdad Desnuda, México, 1833.

Voz de la Patria, 1830.

Bibliografía

Alamán, L. (1834). Defensa del ministro de relaciones D. Lucas Alamán, en la causa formada contra él y contra los ex-ministros de guerra y justicia del vice-presidente D. Anastasio Bustamante, con unas noticias preliminares que dan idea del origen de ésta. Escrita por el mismo ex-ministro quien la dirige a la nación. México: Imprenta de Galván, a cargo de Mariano Arévalo.

Alamán, L. (1852). Historia de México desde los primeros movimientos que prepararon su independencia en el año de 1808 hasta la época presente. v. 5. México: Imprenta de J. M. Lara. 
ANDREws, C. (2004). "Constitución y leyes. El lenguaje liberal y el Plan de Jalapa” en C. Gómez Álvarez y M. Soto (coords.), Transición y cultura política. De la Colonia al México independiente (p. 143-170). México: Universidad Nacional Autónoma de México, Facultad de Filosofía y Letras.

Aquinas, T. (1957). “On Kingship [De Regimine Principum]”, en D. Bingongiari (ed. e intr.). The Political Ideas of St. Thomas Aquinas (p. 175-179). Nueva York: Hafner Publishing Company Inc.

Arrom, S. M. (1988). "Popular Politics in Mexico City: The Parián Riot, 1828”. Hispanic American Historical Review, 68 (n. 2), p. 245-268.

BACHofEn, B. (2011). “Why Rousseau Mistrust Revolutions: Rousseau's Paradoxical Conservatism”, en Holger Ross Lauritsen y Mikkel Thorup (eds.). Rousseau and Revolution (p. 17-30). Londres/Nueva York: Continuum.

Brincat, S. K. (2008). "Death to 'Tyrants': The Political Philosophy of Tyrannicide-Part I". Journal of International Political Theory, v. 4 (2), p. 212-240.

Bustamante, C. M. de (2003). Diario Histórico de México, 1822-1848. J. Z. Vázquez y H. C. Hernández Silva (eds.). CD-ROM 1. México: Centro de Investigaciones y Estudios Superiores de Antropología Social/El Colegio de México.

Chiaramonte, J. C. (2004). "The Principle of Consent in Latin and Anglo-American Independence". Journal of Latin American Studies, v. 36 (n. 3), p. 563-586.

Costeloe, M. P. (1996). La primera república federal de México (1824-1835), Un estudio de los partidos políticos en el México independiente. México: Fondo de Cultura Económica.

Cuevas, L. G. (1954). Porvenir de México. México: Editorial JUS.

Ford, F. L. (1985). Political Murder: From Tyrannicide to Terrorism. Cambridge: Harvard University Press.

Guardino, P. (2005). The Time of Liberty. Popular Political Culture in Oaxaca, 1750-1850. Durham: Duke University Press.

Guerra, F. X. (2000). El pronunciamiento en México: prácticas e imaginarios. Travaux et Recherches dans les Amériques du Centre, n. 37, p. 15-26. 
Herrejón Peredo, C. (1983). "Hidalgo: la justificación de la insurgencia”. Relaciones. Estudios de historia y sociedad, v. Iv (n. 13), p. 31-53.

Hоввеs, T. (1998) Leviathan. J. C. A. Gaskin (ed. e introd.), Oxford: Oxford University Press.

Kern, F. (1939). Kingship and Law in the Middle Ages. I. The Divine Right of Kings and the Right of Resistance in the early Middle Ages, II. Law and Constitution in the Middle Ages. Stanley Bertram Chrimes, (trans. e introd.) Oxford: Basil Blackwell.

Lafragua, J. M. (1987). Ensayo biográfico de Vicente Guerrero. México: Porrúa.

Loвато, J. M. y L. Zavala (2003). "Proclama de los ciudadanos José María Lobato y Lorenzo Zavala”, en C. M. de Bustamante (comp.). J. Z. Vázquez y H. C. Hernández Silva (eds.). Diario Histórico de México, 1822-1848 (1, "anexos”). México: Centro de Investigación y Estudios Superiores en Antropología Social/El Colegio de México.

Locke, J. (1937). "An Essay Concerning the True Original Extent and End of Civil Government”, en Treatise of Civil Government and a Letter Concerning Toleration. Nueva York: Appleton-Century-Crofts.

Locke, J. (1980). Second Treatise of Government. Cambridge: Hackett Publishing Company Inc.

LÓPEZ de Santa AnNa, A. (2003). "Manifiesto que el ejército libertador dirige a los pueblos de Anáhuac”, en C. M. de Bustamante (comp.). J. Z. Vázquez y H. C. Hernández Silva (eds.). Diario Histórico de México, 1822-1848 (1, "anexos"). México: Centro de Investigación y Estudios Superiores en Antropología Social/El Colegio de México.

MARIANA, J. de (1854). “Del rey y de la institución real”, en Obras del padre Juan de Mariana. v. 2. Madrid: M. Ribadeneyra.

Mirkin, H. G. (1972). "Rebellion, Revolution and the Constitution: Thomas Jefferson' Theory of Civil Disobedience”. American Studies, v. 13 (n. 2), p. 61-74.

Noriega, A. (1972). El pensamiento conservador y el conservadurismo mexicano. v. 2. México: Universidad Nacional Autónoma de México, Instituto de Investigaciones Jurídicas. 
PAZ, J. I. (1829). Estupendo grito en la Acordada y verdadero detalle de sus inmarcesibles sucesos desde el domingo 30 de noviembre el año prócsimo pasado, hasta el día 4 de diciembre del mismo, etcétera. México: Imprenta del Correo.

Ramos, S. (1943). Historia de la filosofía en México, v. x. México: Universidad Nacional Autónoma de México Imprenta Universitaria/Biblioteca de filosofía mexicana.

Reyes Heroles, J. (1957-1961). El liberalismo mexicano. 3 v. México, Universidad Nacional Autónoma de México, Facultad de Derecho.

Riva PAlacio, V. (1884-1899). México a través de los siglos. Historia general y completa del desenvolvimiento social, político, religioso, militar, artístico, científico y literario de México desde la antigüedad más remota hasta la época actual. México: Ballescá y Compañía.

Rivera Cambas, M, (1872-1873). D. Manuel Gómez Pedraza. En Los gobernantes de México: galería de biografías y retratos de los Virreyes, Emperadores, Presidentes y otros gobernantes que ha tenido México, desde don Hernando Cortés hasta el C. Benito Juárez. v. 2. México: Imprenta de J. M. Aguilar Ortiz.

Romero VALderrama, A. (2010). "Una controversia en la elección presidencial de 1828: los atributos de las legislaturas ¿̇seleccionar o designar?”, en J. A. Aguilar Rivera (coord.). Las elecciones y el gobierno representativo en México (1810-1910), (p. 165-195). México: Fondo de Cultura Económica/ Consejo Nacional para la Cultura y las Artes.

Romero Valderrama, A. (2017). “Asociación e identidad 'imparcial': una propuesta alternativa a las logias masónicas en la administración de Guadalupe Victoria (1826-1828)". Mexican Studies/Estudios Mexicanos v. 33 (n. 1).

Rousseau, J.-J. (1950). The Social Contract and Discourses. G. Cole (trans.). Nueva York: E. P. Dutton \& Co.

Rousseau, J.-J. (2001). "Letters Written from the Mountain”, en Collected Writings of Rousseau. v. 9. Lebanon, NH: University Press of New England.

Skinner, Q. (1988). "Political Philosophy", en Schmitt Charles et al. (eds.) The Cambridge History of Renaissance Philosophy (p. 389-452). Cambridge: Cambridge University Press. 
Stoetzer, C. (1979). The Scholastic Roots of the Spanish American Revolution. Nueva York: Fordham University Press.

Tornel y Mendívil, J. M. (1985). Breve reseña histórica de los acontecimientos más notables de la República Mexicana. México: Fondo de Cultura Económica/Instituto Helénico.

VatTel, E. de (2008). The Law of Nations, or, Principles of the Law of Nature, Applied to the Conduct and Affairs of Nations and Sovereigns, with Three Early Essays on the Origin and Nature of Natural Law and on Luxury. Béla Kapossy y Richard Whatmore (eds. e entrods.). Indianápolis: Liberty Fund.

VÁzquez Semadeñ, M. E. (2010). La formación de una cultura política republicana. El debate público sobre la masonería, México, 1821-183o. México: Universidad Nacional Autónoma de México/El Colegio de Michoacán.

Villavicencio, P. ['El Payo del Rosario'] (1827). Manifiesto del Payo del Rosario a sus compatriotas, o sea suplemento a la memoria del sr. Iturbide. México: Imprenta de la ex-inquisición.

Weinstock, D. y C. Nadeau (eds.) (2004). Republicanism: History, Theory and Practice. Londres: Frank Cass.

S/A (1828). "Ya se zurra, ya se zurra, don Guadalupe Victoria... pero se zurra en las logias”. México: Imprenta de Alejandro Valdés, a cargo de José María Gallegos.

Zavala, L. (1845). Ensayo histórico de las revoluciones de México desde 1808 hasta 1830. 2 v. México: Imprenta a cargo de Manuel N. de la Vega.

Zerecero, A. (1975). Memorias para la historia de las revoluciones de México. México: Universidad Nacional Autónoma de México. 